\title{
SURGICAL TREATMENT OF THORACOLUMBAR FRACTURES
}

\author{
Osmar Avanzi, Robert Meves, Maria Fernanda Silber Caffaro
}

\section{ABSTRACT}

Introduction: Several factors are responsible for the late diagnosis of thoracolumbar burst fractures; however, few papers have been published concerning the treatment of these fractures weeks after the original trauma. Objective: This is a retrospective study aimed to verify treatment outcomes of patients submitted to arthrodesis and posterior instrumentation three to five weeks after thoracolumbar burst fractures. Patients and Method: From 1980 to 2004, excluding patients with sequelae or recent fractures, 15 cases were identified with a minimum follow-up period of one year. Results: From the clinical viewpoint, 10 patients were asymptomatic and according to the Frankel scale, three of the five patients that presented neurological changes showed improvement (60\%). One patient presented superficial infection and sphincter dysfunction. $X$-ray studies demonstrated kyphosis on fracture site to be the main complication, affecting five patients (33\%). There was a mean 3 degree worsening of the kyphosis compared to the values found on early X-ray images. Conclusion: We believe, based on a postoperative kyphosis perspective, that subacute thoracolumbar burst fractures should be treated in a specific manner.

Keywords: Spine fractures. Spinal cord injuries. Wounds and injuries.

Citation: Avanzi O, Chih LY, Meves R, Caffaro MFS. Surgical treatment of thoracolumbar fractures. Acta Ortop Bras. [online]. 2009; 17(1):9-12. Available from URL: http:// www.scielo.br/aob.

\section{INTRODUCTION}

Many authors describe the experience acquired concerning the approach and treatment of thoracolumbar burst fracture especially the acute fracture or its sequels, however few articles report about subacute fracture, i.e., operated after some weeks of the original trauma. ${ }^{1}$ Many authors, such as Roberson and Whitesides $^{2}$, Kostuik and Matsusaki ${ }^{3}$, Transfeld et al. ${ }^{4}$, Chang ${ }^{5}$ and Bolhman et al. ${ }^{6}$; assess patients with over 3 months between trauma and surgery, showing the need of having different surgical tactics for recent fractures such as the double access approach and higher complication rate. Chadha and Bahadur ${ }^{1}$, consider patients treated with three weeks after trauma, showing their results with the posterior access approach. There are many causes for treatment delay of these fractures, such as the lack of resources in primary care, delay on removing a patient to suitable centers; Multiple trauma patients or those with respiratory and vascular problems who need to be treated first, as well as diagnostic failures in primary care..$^{1,-9}$

The purpose of this paper was to provide a retrospective survey of patients having thoracolumbar burst fractures and to a assess the results of patients treated with arthrodesis and posterior metal instrumentation with three to five weeks of trauma, therefore excluding patients with sequels or recent fracture.

\section{PATIENTS AND METHODS}

From 1980 to 2004, 267 patients were hospitalized with thoracolumbar burst fractures according to Denis classification. ${ }^{10}$ Surgery was indicated for fractures regarded as mechanically unstable or in the presence of a neurological picture. We included in this study patients submitted to posterior arthrodesis with metal instrumentation and posterior spinal cord decompression when the patient presented with neurological dysfunction within three to five weeks of trauma.

Of the total of 30 patients, 15 presented clinical and radiographic evaluation consistent to medical records. The average time elapsed between fracture and surgical treatment was four weeks. The minimum postoperative follow up time was twelve months and the maximum was 129 months (mean:44 months).

Concerning the reasons for delayed surgical treatment, in this group we saw a delay on removing the patient to this service in nine cases; failure of the treatment with orthopaedic vest which were subsequently treated with surgery for presenting progressive kyphosis worsening at fracture site in three cases and associated clinical or surgical disease delaying the orthopaedic procedure in three patients.

The highest incidence of the kind of trauma responsible for fracture was high fall in eight patients (53\%), followed by car accident in four patients (27\%).(Table 1) Ten patients (67\%) were male and five (33\%) female, while age ranged from 14 to 55 years, with a mean of 33 years old. Concerning associated injuries, six patients $(61 \%)$ presented fractures on ends, with femoral and calcaneus ends being the most frequent. On spine, L1 was affected in five patients (33\%), followed by $\mathrm{T} 12$ and L3 respectively in four (27\%) and two patients (13\%). Concerning the

All authors state no potential conflict of interest concerning this article

Department of Orthopaedics and Traumatology, Medical Sciences School, Santa Casa de Misericórdia de São Paulo

Correspondences to: Group of Spine, Department of Orthopaedics and Traumatology, Medical Sciences School, Santa Casa de Misericórdia de São Paulo.

Rua Dr. Cesário Motta Jr.,61 - Vila Buarque - São Paulo, SP, Brasil - CEP 01221-020.

E-mail: coluna@santacasasp.org.br; robertmeves@hotmail.com 
Table 1 - Changes on Frankel scale.

\section{FOLLOW-UP}

\begin{tabular}{c|c|c|c|c|c}
\hline Initial & A & B & C & D & E \\
\hline A & & & & & \\
\hline B & & 1 & & & 1 \\
\hline C & & & & & \\
\hline D & & & & 1 & 2 \\
\hline E & & & & & 10 \\
\hline
\end{tabular}

Source: Medical File Service, Santa Casa de São Paulo

neurological picture, 10 patients (66\%) had no degree of compromise while five patients (34\%) showed incomplete injury. the posterior approach with the use of a metallic implant was performed in all patients (Table 2).

Table 2 - Instruments used for posterior arthrodesis.

\begin{tabular}{c|c|c}
\hline Instrument & Nr. of Patients & $\%$ \\
\hline Harri-Luque & 8 & 53 \\
\hline CD & 3 & 20 \\
\hline Harstchill & 3 & 7 \\
\hline Lea Plaza & 1 & 100 \\
\hline Total & 15 & 20 \\
\hline
\end{tabular}

Source: Medical File Service, Santa Casa de São Paulo

For assessing the functional picture, we studied the current symptoms of the patient and his/her neurological picture, according to the scale proposed by Frankel et al. ${ }^{11}$; and for studying thoracolumbar kyphosis we used preoperative and late follow up X-ray imaging by the method of Cobb. ${ }^{12}$

\section{RESULTS}

From a clinical picture perspective, 10 (67\%) patients were asymptomatic; two (12\%) complained of lumbalgia upon physical effort; one $(7 \%)$ complained of subjective lumbocyatalgia upon ambulation; one $(7 \%)$ of pain on skin implant protuberance and one $(7 \%)$ of urinary sphincter dysfunction.

According to Frankel et al. ${ }^{11}$ classification, of the five patients with primarily incomplete injury, three (60\%) improved and two (40\%) remained unchanged.(Table 1)

Concerning complications resulting from surgical treatment, one patient (7\%) had a sphincter change after posterior surgery remaining unchanged after spinal cord decompression through anterior approach and one patient (7\%) showed superficial infection resolved with clinical treatment.

Regarding the aesthetic of the sagittal alignment of the thoracolumbar spine, of the 11 patients (73\%) having kyphosis resulting from fracture, five (45\%) remained unchanged and four (36\%) worsened their X-ray measurement. In those 4 patients (27\%) who had no kyphosis, one (25\%) got worse and three patients (75\%) remained unchanged. We must emphasize that of the 15 patients treated, five (33\%) got worse, eight (53\%) remained unchanged and only two (14\%) improved.(Table 3)

Concerning the angular value of kyphosis, the average preoperative measurement was $17^{\circ}$ and $20^{\circ}$ as mean final value, reflecting a mean worsening of $3^{\circ}$ postoperatively.

Table 3 - Distribution of patients versus kyphosis at fracture site.

\begin{tabular}{c|c|c|c|c}
\hline Pre-Op & Patients & Improvement & Worsening & Unchanged \\
\hline w/kyphosis & 11 & 2 & 4 & 5 \\
\hline w/o kyphosis & 4 & 0 & 1 & 3 \\
\hline Total & 15 & 2 & 5 & 8 \\
\hline
\end{tabular}

Source: Medical File Service, Santa Casa de São Paulo

\section{DISCUSSION}

A large portion of the papers addressing the treatment of thoracolumbar fractures concern recent fractures. ${ }^{3,4,10}$ Burst injuries account for about $60 \%$ of the thoracolumbar fractures on multiple trauma patients. Of these, diagnostic delays due to reasons similar to those presented in this paper occur in up to $24 \%$ of the patients. ${ }^{13}$ It is worthy to mention, however, the scarcity of literature reports concerning the treatment of these fractures. regarding the causes responsible for delayed treatment, diagnostic failure is one of the main factors. Bolhman et al. ${ }^{6}$ assessed many kinds of fracture on spine including thoracolumbar fractures and mentioned 30\% diagnostic failure rate on primary care. Chang ${ }^{5}$ described $12 \%$, as well as Enderson et al. ${ }^{14}$ and Laasonen and Kivioja ${ }^{15}$ showed 12\% and $4 \%$, respectively

Stanislas et al. $^{8}$ mentioned precarious early clinical examination and failures on the interpretation of signs and symptoms resulting from complex situations, such as for example in alcohol, drug addicted patients or those in deep coma according to Glasgow Scale, as the major factors responsible for diagnostic failure in primary care.

Reid et al. ${ }^{7}$ emphasized the importance of providing an early diagnosis of thoracolumbar fracture whit neurological picture, finding an incidence of $1 \%$ of neurological conditions in recent fractures and $10 \%$ for fractures diagnosed later.

Challenges may be found in determining the minimum time elapsed from trauma to consider surgical treatment as being late or fracture-sequel. Roberson and Whitesides ${ }^{2}$, reviewing surgical reconstruction of post-trauma kyphosis in 64 patients with over three months of fracture using a surgical approach through anterior access or associated to posterior stabilization, reported neurological improvement in 13 of 18 patients with neurological picture. These authors show complications in $24 \%$ of the treated patients, as well as a death due to pulmonary thromboembolism.

Kostuik and Matsusaki in a study about stabilization, instrumentation and decompression through anterior approach on post trauma kyphosis in 37 patients at least with six months from fracture, found partial neurological improvement in five of the eight patients with neurological dysfunction with three of them remaining unchanged. Transfeld et al. ${ }^{4}$ reviewed 49 patients with neurological lesion submitted to anterior decompression and stabilization 
through posterior approach in fractures treated with over three months of trauma. Although they have showed a large number of complications postoperatively, they mention neurological improvement in $18 \%$ of the patients and $6 \%$ improvement of kyphosis on fractured region.

Clohisy et al. ${ }^{16}$ assessed the results of spinal cord decompression through anterior approach in 22 patients with incompletetype neurological picture treated after seven to 180 days of trauma. They noticed that neurological improvement is higher in the group treated within up two 48 hours from trauma. Of tem 12 complications reported, they described two patients with pseudoarthrosis.

Chang $^{5}$ in a paper about post trauma angular kyphosis correction on thoracolumbar spine, described an average correction of 10-14 degrees, with an initial mean value of 39 degrees, performing a double surgical approach, both anterior and posterior, at the same surgical time. All the 17 patients had three years as minimum time from trauma and they had no postoperative complications, although one patient had presented paralytic ileum and two patients presenting urinary infection. The author didn't find neurological deterioration in none of the six patients with neurological picture preoperatively. He also reinforced the importance of preventing vertebral collapse with the anterior approach.

Bohlman et al. ${ }^{6}$ reported a study about the results of surgical treatment with anterior approach in 45 patients, with vertebral pain and/ or neurological picture, operated at least within three months of trauma. They mentioned the degree of pain improvement achieved in 41 of the 44 patients and some neurological recovery in 21 of the 25 patients who presented incomplete-type neurological picture. They found six orthopaedic complications, one of them due to pseudoarthrosis, one patient who showed postoperative bowel occlusion, and another who evolved to death due to pulmonary thromboembolism. In 2004, Been et al. ${ }^{17}$ selected 25 Magerl et al. ${ }^{18}$ type-A compressive thoracolumbar fracture victims operated after six months of trauma. the authors assessed two groups of patients: one submitted to the approach with anterior instrumentation, and another through double approach. No difference was found concerning kyphosis correction loss having also noticed a poor neurological recovery between both groups despite a significant improvement of complaints of spinal pain.

Chadha and Bahadur ${ }^{1}$ studied two groups of patients with thoracolumbar fractures defining the group of late fractures the one constituted of patients with at least three weeks of trauma. In this group six patients were studied, where a mean 8-degree improvement of kyphosis was achieved by surgery through posterior approach and third-generation instrumentation, considering 20 degrees as minimum preoperative deformity. They also found an improvement of the neurological picture in $44 \%$ of the patients, according to Frankel et al. ${ }^{11}$ classification. They mentioned 11 complications in six operated patients specifically related to metal implant and one patient evolved to death due to postoperative sepsis.

In our series, we studied 15 patients treated within a minimum of three weeks and maximum of five weeks of the trauma having thoracolumbar burst fractures according to Denis ${ }^{10}$ classification. We found improvement of the neurological picture in $60 \%$ of our patients.

We must consider that the patients operated within less than five weeks from fracture should be more likely to present improved neurological picture than those treated after over three months. ${ }^{\text {- }}$ 3,5,6,19 The same rationale must also be considered when pre and postoperative kyphosis behavior and the complications found are assessed. The worsening of the mean angular kyphosis found in our paper can be justified by the delayed surgical treatment and to the absence of appropriate anterior support. Criteria for indicating additional anterior arthrodesis after posterior instrumentation of acute fractures are discussed by many authors $^{19-21}$, however studies addressing sub-acute fractures are scarce.

Transfeldt et al. ${ }^{4}$ and Chang ${ }^{5}$ noticed kyphosis improvement, but included patients treated within over three months of fracture in which they used both approaches (anterior and posterior). Chadha and Bahadur ${ }^{1}$, in turn, used a third-generation implant with pedicular screws, which presented stronger biomechanic stiffness but a higher complication rate related to metal implant.

Surgical approach on acute phase may be, according to surgeon's preference, performed through anterior or posterior access. ${ }^{20}$ In the sequel phase and the resulting aesthetic deformity with kyphosis and, many times, in the presence of a neurological picture, the preference is for correction through anterior and posterior access. ${ }^{4}$ But, on sub-acute fracture (three to five weeks), how should surgical treatment be provided? In patients included in the group of posterior approach only we found a significant improvement (60\%) for neurological picture recovery concerning kyphosis: of the 15 patients treated, five (33\%) worsened, eight (53\%) remained unchanged, and only two (14\%) improved. We understand that the criteria for indicating associated anterior arthrodesis should be discussed in this particular group of subacute thoracolumbar burst fracture patients submitted to current third generation implants.

Concerning postoperative complications, we found few in our study, although one of the patients remains with neurological sequel after surgical treatment, as oppositely to the study by Chadha and Bahadur. ${ }^{1}$

\section{ACKNOWLEDGEMENTS}

We acknowledge the Publication Support Nucleus, Medical Sciences School, Santa Casa de São Paulo - NAP-SC for its technical-scientific support to the publication of this manuscript. 


\section{REFERENCES}

1. Chadha M, Bahadur R. Steffee variable screw placement system in the management of unstable thoracolumbar fractures: a Third World experience. Injury. 1998;29:737-42.

2. Roberson JR, Whitesides TE Jr. Surgical reconstruction of late post-traumatic thoracolumbar kyphosis. Spine. 1985;10:307-11.

3. Kostuik JP, Matsusaki H. Anterior stabilization, instrumentation, and decompression for post-traumatic kyphosis. Spine. 1989;14:379-86.

4. Transfeldt EE, White D, Bradford DS, Roche B. Delayed anterior decompression in patients with spinal cord and cauda equina injuries of the thoracolumbar spine. Spine. 1990;15:953-7.

5. Chang WK. Oligosegmental correction of post-traumatic thoracolumbar angular kyphosis. Spine. 1993;18:1909-15.

6. Bohlman HH, Kirkpatrick JS, Delamarter RB, Leventhal M. Anterior decompression for late pain and paralysis after fractures of the thoracolumbar spine. Clin Orthop Relat Res. 1994;300:24-9.

7. Reid DC, Henderson R, Saboe L, Miller JD. Etiology and clinical course of missed spine fractures. J Trauma. 1987;27:980-6.

8. Stanislas MJ, Latham JM, Porter KM, Alpar EK, Stirling AJ. A high risk group for thoracolumbar fractures. Injury. 1998;29:15-8.

9. Prasad VS, Vidyasagar JV, Purohit AK, Dinakar I. Early surgery for thoracolumbar spinal cord injury: initial experience from a developing spinal cord injury centre in India. Paraplegia. 1995;33:350-3.

10. Denis $F$. The three column spine and its significance in the classification of acute thoracolumbar spinal injuries. Spine. 1983;8:817-31.

11. Frankel HL, Hancock DO, Hyslop G, Melzak J, Michaelis LS, Ungar GH et al. The value of postural reduction in the initial management of closed injuries of the spine with paraplegia and tetraplegia. I. Paraplegia. 1969;7:179-92.

12. Cobb JR. Outline for the study of scoliosis. Instr Course Lect. 1948;5:261-75.

13. Dai LY, Yao WF, Cui YM, Zhou Q. Thoracolumbar fractures in patients with multiple injuries: diagnosis and treatment-a review of 147 cases. J Trauma. 2004;56:348-55.

14. Enderson BL, Reath DB, Meadors J, Dallas W, DeBoo JM, Maull KI. The tertiary trauma survey: a prospective study of missed injury. J Trauma. 1990;30:666-9.

15. Laasonen EM, Kivioja A. Delayed diagnosis of extremity injuries in patients with multiple injuries. J Trauma. 1991;31:257-60.

16. Clohisy JC, Akbarnia BA, Bucholz RD, Burkus JK, Backer RJ. Neurologic recovery associated with anterior decompression of spine fractures at the thoracolumbar junction (T12-L1). Spine. 1992; 17:325-30.

17. Been HD, Poolman WR, Ubags LH. Clinical outcome and radiographic results after surgical treatment of post-traumatic thoracolumbar kyphosis following simple type A fractures. Eur Spine J. 2004;13:101-7.

18. Magerl F, Aebi M, Gertzbein SD, Harms J, Nazarian S. A comprehensive classification of thoracic and lumbar injuries. Eur Spine J. 1994;3:184-201.

19. Parker JW, Lane JR, Karaikovic EE, Gaines RW. Successful short-segment instrumentation and fusion for thoracolumbar spine fractures: a consecutive 41/2-year series. Spine. 2000;25:1157-70.

20. Ghanayem AJ, Zdeblick TA. Anterior instrumentation in the management of thoracolumbar burst fractures. Clin Orthop Relat Res. 1997;335:89-100.

21. Dai LY, Jin WJ. Interobserver and intraobserver reliability in the load sharing classification of the assessment of thoracolumbar burst fractures. Spine. 2005;30:354-8. 